\title{
Body Weight at Birth and at Age Three and Respiratory Illness in Preschool Children
}

\author{
Yoolwon Jeong ${ }^{1}$, Kyunghee Jung-Choi ${ }^{1}$, Jin Hwa Lee ${ }^{2}$, Hwa Young Lee ${ }^{3}$, Eun Ae Park \\ Young Ju Kim ${ }^{5}$, Eunhee Ha ${ }^{1}$, Se-Young Oh$^{6}$, Hyesook Park ${ }^{1}$
}

\begin{abstract}
${ }^{1}$ Department of Preventive Medicine, School of Medicine, Ewha Womans University; ${ }^{2}$ Department of Internal Medicine, School of
Medicine, Ewha Womans University; ${ }^{3}$ Department of Anatomy, School of Medicine, Ewha Womans University; ${ }^{4}$ Department of Pediatrics, School of Medicine, Ewha Womans University; ${ }^{5}$ Department of Obstetrics \& Gynecology, School of Medicine, Ewha Womans University; ${ }^{6}$ Department of Food \& Nutrition, College of Human Ecology, Kyung Hee University
\end{abstract}

\begin{abstract}
Objectives: The purpose of this study was to examine the associations of current body weight and body mass index (BMI) at age three and birth weight in developing chronic respiratory illness in childhood and identify possible interaction underlying its mechanism.

Methods: The study was carried out with 422 children who were enrolled in a hospital-based birth cohort. Birth related anthropometric data were collected at birth. At age 3 years, the presence of respiratory symptoms was evaluated by using the Korean version of core questionnaire for wheezing and asthma from the International Study of Asthma and Allergies in Childhood (ISAAC). Physical examination was carried out to measure the child's weight and height.

Results: Children in the lowest birth weight tertile $(\mathrm{aOR}=3.97,95 \% \mathrm{Cl}=0.94-16.68)$ or highest $\mathrm{BMI}$ tertile $(\mathrm{aOR}=3.68$, $95 \% \mathrm{Cl}=1.24-10.95)$ at three years of age were at an increased risk of chronic respiratory illness. Children who were initially in the lowest birth weight tertile but now belong in the highest weight tertile had higher risk of chronic respiratory illness compared to those who had remained in the middle tertile $(\mathrm{OR}=16.35,95 \% \mathrm{Cl}=1.66-160.57)$.

Conclusions: Children with lower birth weight or higher BMI were at an increased risk of chronic respiratory illness. In addition, children who were initially in the lowest birth weight tertile but are now in the highest weight tertile had higher risk of chronic respiratory illness compared to those who remained in the middle tertile.
\end{abstract}

Key words: Birth weight, Obesity, Body weight changes, Preschool child, Respiratory signs and symptoms J Prev Med Public Health 2010;43(5):369-376

\section{INTRODUCTION}

Chronic respiratory illness is common in young children and is a major cause of disability, hospitalization, and activity restriction in children $[1,2]$. Its prevalence has been increasing during the past several decades in many parts of the world [3-5]. The prevalence of asthma, which is the most common cause of chronic childhood disease in developed countries, has nearly doubled over the last 2 decades, putting a serious socioeconomic burden on the children, their parents, and the community as well [2]. Similar trend has been observed in Korea, as epidemiological studies estimated an increase from 3.4\% prevalence of asthma in 1964 to $13.4 \%$ in 1995 [5].

Accumulating epidemiological evidence suggests that overweight status and obesity may play a role in the development of chronic respiratory illness $[1,2]$. Numerous studies carried out with adults support the hypothesis that obesity is associated with an increased risk of asthma and other respiratory symptoms [6-8]. Although the parallel increase in the prevalence of childhood obesity and asthma during the past several decades is suggested to be an evidence of a possible association between the two factors, studies that have investigated this relationship in children showed controversial results [1,9-11].

Perinatal factors have been suggested to be risk factors of chronic respiratory illness in childhood as the development and maturation of lung function starts well before birth. Among many perinatal factors, birth weight is recognized as an indicator reflecting fetal growth and maturation $[12,13]$ and is suggested to be directly associated with weight and obesity of childhood [2,3]. However, previous studies on birth weight and the risk of chronic respiratory illness in childhood are contradictory, showing direct $[4,14]$, inverse $[3,15]$ as well as null associations $[2,16]$.

As weight is a condition that is continuously changing with growth, not only single point weight measurements 
but also the pattern of weight change should be investigated. Recent epidemiological data suggest that the most common growth pattern associated with an increase in later disease risk is the combination of relatively lower birth weight and subsequent overweight status in childhood or adolescence $[17,18]$. Accumulating epidemiologic evidence supports that such pattern of weight gain increases the risk of type 2 diabetes [19], cardiovascular diseases [20-22] and. However, studies with chronic respiratory diseases presented conflicting results, showing that lower birth weight and subsequent overweight status increases the risk [20,21] or were protective of respiratory illnesses [22,23]. This association of growth pattern and disease risk is suggested to be, at least in part, explained by an interaction of birth weight and current obesity status [21].

The purpose of this study was to examine the associations of obesity and birth weight with chronic respiratory illness and identify possible interaction of current obesity and birth weight on the risk of chronic respiratory illness in preschool children.

\section{MATERIALS AND METHODS}

\section{Study Population}

Healthy pregnant women who had visited Ewha Womans University Hospital from 2001 to 2006 for prenatal care at 24-28 weeks gestation were informed of the study and recruited upon approval. New-born babies from these women were enrolled into the cohort and this resulted in a cohort of 1436 babies. Birth related anthropometric data such as birth weight and gestational age were collected at birth. A detailed questionnaire and physical examination was scheduled when the child reached age three. Parents of 630 children were successfully contacted to be informed of the schedule. Subsequently, 424 children at age 3 were submitted to a physical examination and parent survey from 2005 to 2009. In the final analysis, 422 children were included due to incomplete information of respiratory illness history in 2 children. The Institutional Review Board on Human Subjects at Ewha Womans University, had approved the study protocol and an informed consent was obtained from all the participants.

\section{Data Collection}

The children's birth weight and gestational age were recorded at birth by trained nurses working in delivery rooms. At 3 years of age, these children were submitted to a physical examination to have their weight and height measured. Height was measured with a digital stadiometer to the nearest $0.1 \mathrm{~cm}$ with the child's shoes taken off. Weight was measured with a well-calibrated digital weight scale to the nearest $0.1 \mathrm{~kg}$. Body mass index (BMI) was calculated as weight in kilograms divided by height in meters squared.

The parents of each 3-year old child underwent a comprehensive questionnaire which included questions about respiratory illness and socio-demographic factors. The details of the questionnaire and physical examination were explained to the parents by a trained research coordinator. Once the parents have agreed to participate, the questionnaire on respiratory illness and socio-demographic information were sent to the parents, filled out, and returned. Presence of wheezing, frequent cough, and asthma were evaluated by using the Korean version of core questionnaire for wheezing and asthma from the International Study of Asthma and Allergies in Childhood (ISAAC) of which the validity has been proven in another study [24]. Asthma was defined as being diagnosed with asthma or taking anti-asthmatic medications. Wheezing was defined as having any one of the following within the last 12 months: more than one attack of wheeze, sleep-disturbing wheeze, speechlimiting wheeze, or exercise-induced wheeze. Frequent cough was defined as suffering cough occurring outside colds during the last 12 months. Chronic respiratory illness was defined as being diagnosed with a chronic respiratory disease or suffering from respiratory symptoms, such as cough and sputum, for more than 3 months. Monthly household income, mother's employment status, prenatal and postnatal environmental tobacco smoke (ETS) exposure was surveyed as they are known as possible confounding factors [1-4,9,11]. Prenatal ETS exposure was defined as mother smoking during gestation and postnatal ETS exposure was defined as child being exposed to tobacco smoke in the household. Family history of allergic diseases was defined as any member of their 1st and 2nd degree relatives having any one of the following diseases: allergic rhinitis, asthma, and atopic dermatitis.

\section{Statistical Analysis}

All the obesity indexes were divided into tertiles for analysis. To examine the prevalence of respiratory symptoms by weight and obesity index tertiles, Pearson chi-squared test and trend test was used. Logistic regression was used to estimate the risk of respiratory 
Table 1. General characteristics of the study population

\begin{tabular}{lc}
\hline & $\mathrm{n}(\%)$ \\
\hline Total (n) & 422 \\
Boys & $209(49.5)$ \\
At birth, mean (SD) & $2962(630)$ \\
Birth weight (g) & $37.9(2.6)$ \\
Gestational age (wk) & \\
At 3 years of age, mean (SD) & $14.6(1.9)$ \\
Weight (kg) & $97.2(4.5)$ \\
Height (cm) & $15.2(1.3)$ \\
BMl (kg/m²) & \\
Disease/symptom prevalence & $43(10.2)$ \\
Chronic respiratory illness & $23(5.5)$ \\
Asthma & $68(16.1)$ \\
Wheezing & $74(17.5)$ \\
Frequent cough & $2(0.6)$ \\
Monthly household Income (KRW) & $40(11.3)$ \\
1000000 - 2000000 & $85(24.0)$ \\
2000000 - 3000000 & $159(44.9)$ \\
3000000 - 5000000 & $68(19.2)$ \\
& \\
Mother's employment* & $115(33.2)$ \\
Yes & $231(66.8)$ \\
No & \\
ETS exposure & $74(17.5)$ \\
Yes & $348(82.5)$ \\
No & \\
Family history of allergic diseases & \\
Yes & $22(5.3)$ \\
No & $395(94.7)$ \\
\hline ST &
\end{tabular}

SD: Standard Deviation, KRW: Korea won.

* Mother's employment at the time of survey.

ETS exposure is defined as prevalence of prenatal or postnatal environmental tobacco smoke exposure based on the survey questionnaire.

* Allergic diseases include allergic rhinitis, asthma, and atopic dermatitis. symptoms by obesity index tertiles after adjusting for sex, gestational age, household income, mother's employment, ETS, and family history of allergic diseases. All data analysis was carried out by using SAS statistical package, version 9.1 (SAS Inc., Cary, NC, USA). $p$ value of $<0.05$ was considered to be statistically significant.

\section{RESULTS}

The total number of participants included in the final analysis was 422, of which 209 (49.5\%) were boys (Table 1). Mean birth weight of the children was $2962 \mathrm{~g}$. Mean weight at 3 years of age was $14.6 \mathrm{~kg}$. The prevalence of chronic respiratory illness and asthma was $10.2 \%$ and $5.5 \%$, respectively. During the last 12 months $16.1 \%$ of the participants had experienced wheezing and $17.5 \%$ had frequent cough.

Prevalence of respiratory symptoms was analyzed by tertiles of birth weight, weight at age 3, and BMI at age 3 (Table 2). The prevalence of chronic respiratory illness was the highest in the lowest birth weight tertile, although this was not significant. At 3 years of age, prevalence of chronic respiratory illness in the highest weight and BMI tertile was $17.9 \%(\mathrm{p}=0.001)$ and $19.6 \%$ $(\mathrm{p}<0.0001)$, respectively. There was an increase in the prevalence of chronic respiratory illness according to an increase in weight $(\mathrm{p}$-trend $=0.001)$ and BMI $(\mathrm{p}$-trend $<$ $0.001)$. The prevalence of asthma, wheezing, and frequent cough also significantly increased with an increase in BMI tertiles ( $\mathrm{p}$-trend $=0.03$ ).

Table 2. Prevalence of respiratory symptoms by tertiles of birthweight, current weight, and body mass index (BMI) at age three

\begin{tabular}{|c|c|c|c|c|c|c|c|c|}
\hline \multirow[b]{2}{*}{ Index } & \multicolumn{2}{|c|}{ Chronic respiratory illness } & \multicolumn{2}{|c|}{ Asthma } & \multicolumn{2}{|c|}{ Wheezing } & \multicolumn{2}{|c|}{ Frequent cough } \\
\hline & n (\%) & $\begin{array}{l}\text { p-value } \\
\text { (p-trend) }\end{array}$ & n (\%) & $\begin{array}{l}p \text {-value } \\
\text { (p-trend) }\end{array}$ & n (\%) & $\begin{array}{l}p \text {-value } \\
\text { (p-trend) }\end{array}$ & n (\%) & $\begin{array}{l}\mathrm{p} \text {-value } \\
\text { (p-trend) }\end{array}$ \\
\hline \multicolumn{9}{|l|}{ At birth } \\
\hline Birth weight $(g)^{*}$ & & $0.19(0.32)$ & & $0.05(0.59)$ & & $0.21(0.41)$ & & $0.50(0.26)$ \\
\hline Lowest third & $19(13.7)$ & & $4(2.9)$ & & $17(12.3)$ & & $20(14.5)$ & \\
\hline Middle third & $10(7.2)$ & & $13(9.3)$ & & $28(20.0)$ & & $26(18.6)$ & \\
\hline Highest third & $14(10.1)$ & & $6(4.4)$ & & $22(15.9)$ & & $27(19.6)$ & \\
\hline \multicolumn{9}{|l|}{ At 3 years } \\
\hline Weight $(\mathrm{kg})^{+}$ & & $0.001(0.001)$ & & $0.57(0.30)$ & & $0.53(0.27)$ & & $0.74(0.46)$ \\
\hline Lowest third & $8(5.8)$ & & $6(4.4)$ & & $19(13.8)$ & & $22(15.9)$ & \\
\hline Middle third & $10(7.3)$ & & $7(5.1)$ & & $21(15.3)$ & & $23(16.8)$ & \\
\hline Highest third & $25(17.9)$ & & $10(7.1)$ & & $26(18.6)$ & & 27 (19.3) & \\
\hline $\mathrm{BMI}\left(\mathrm{kg} / \mathrm{m}^{2}\right)^{\dagger}$ & & $<0.0001(<0.0001)$ & & $0.05(0.03)$ & & $0.07(0.03)$ & & $0.11(0.03)$ \\
\hline Lowest third & $7(5.1)$ & & $5(3.6)$ & & $14(10.1)$ & & $17(12.3)$ & \\
\hline Middle third & $9(6.5)$ & & $5(3.6)$ & & 25 (18.0) & & $25(18.0)$ & \\
\hline Highest third & 27 (19.6) & & $13(9.4)$ & & 27 (19.6) & & $30(21.7)$ & \\
\hline
\end{tabular}

*Birth weight: lowest third (<2800g), middle third $(2800-3300 \mathrm{~g})$, highest third $(>3300 \mathrm{~g})$.

Weight: lowest third $(13.8 \mathrm{~kg})$, middle third $(13.8-15.3 \mathrm{~kg})$, highest third $(>15.3 \mathrm{~kg})$.

"BMI: lowest third $\left(<14.8 \mathrm{~kg} / \mathrm{m}^{2}\right)$, middle third $\left(14.8-16.0 \mathrm{~kg} / \mathrm{m}^{2}\right)$, highest third $\left(>16.0 \mathrm{~kg} / \mathrm{m}^{2}\right)$. 
Table 3. Adjusted odds ratio of respiratory symptoms by tertiles of birthweight, current weight, and body mass index (BMI) at age three

\begin{tabular}{|c|c|c|c|c|c|c|c|c|}
\hline & \multicolumn{2}{|c|}{ Chronic respiratory illness } & \multicolumn{2}{|c|}{ Asthma } & \multicolumn{2}{|c|}{ Wheezing } & \multicolumn{2}{|c|}{ Frequent cough } \\
\hline & aOR & $95 \% \mathrm{Cl}$ & aOR & $95 \% \mathrm{Cl}$ & aOR & $95 \% \mathrm{Cl}$ & aOR & $95 \% \mathrm{Cl}$ \\
\hline \multicolumn{9}{|l|}{ At birth } \\
\hline \multicolumn{9}{|l|}{ Birth weight $(\mathrm{g})^{*}$} \\
\hline Lowest third & 3.97 & $0.94-16.68$ & 0.29 & $0.05-1.59$ & 1.26 & $0.44-3.55$ & 1.51 & $0.49-4.63$ \\
\hline Middle third & 1.00 & & 1.00 & & 1.00 & & 1.00 & \\
\hline Highest third & 1.15 & $0.33-3.91$ & 0.56 & $0.16-1.96$ & 0.73 & $0.34-1.55$ & 0.74 & $0.32-1.71$ \\
\hline \multicolumn{9}{|l|}{ At 3 years } \\
\hline \multicolumn{9}{|l|}{ Weight $(\mathrm{kg})^{+}$} \\
\hline Lowest third & 0.61 & $0.15-2.45$ & 1.19 & $0.30-4.71$ & 0.97 & $0.43-2.20$ & 1.06 & $0.43-2.62$ \\
\hline Middle third & 1.00 & & 1.00 & & 1.00 & & 1.00 & \\
\hline Highest third & 2.19 & $0.70-6.78$ & 1.70 & $0.44-6.53$ & 1.29 & $0.59-2.80$ & 1.69 & $0.72-3.95$ \\
\hline \multicolumn{9}{|l|}{$\mathrm{BMI}\left(\mathrm{kg} / \mathrm{m}^{2}\right)^{+}$} \\
\hline Lowest third & 0.64 & $0.16-2.49$ & 1.31 & $0.32-5.34$ & 0.68 & $0.30-1.51$ & 0.96 & $0.40-2.29$ \\
\hline Middle third & 1.00 & & 1.00 & & 1.00 & & 1.00 & \\
\hline Highest third & 3.68 & $1.24-10.95$ & 4.28 & $1.17-15.57$ & 1.59 & $0.75-3.35$ & 2.06 & $0.91-4.67$ \\
\hline
\end{tabular}

\section{Cl: confidence interval.}

aOR: odds ratio adjusted by sex, gestational age, household income, mother's employment, prenatal or postnatal environmental tobacco smoke exposure, and family history of allergic disease.

*Birth weight: lowest third (<2800 g), middle third (2800-3300 g), highest third. (>3300 g).

Weight: lowest third (13.8 kg), middle third (13.8-15.3kg), highest third. (>15.3kg).

${ }^{*}$ BMl: lowest third $\left(<14.8 \mathrm{~kg} / \mathrm{m}^{2}\right)$, middle third $\left(14.8-16.0 \mathrm{~kg} / \mathrm{m}^{2}\right)$, highest third. $\left(>16.0 \mathrm{~kg} / \mathrm{m}^{2}\right)$.

Table 4. Adjusted odds ratio of chronic respiratory illness by tertiles of birthweight, current weight, and body mass index (BMI) at age three

\begin{tabular}{|c|c|c|c|c|c|c|}
\hline & \multicolumn{3}{|c|}{ Weight at age three } & \multicolumn{3}{|c|}{$\mathrm{BMI}$ at age three } \\
\hline & Lowest tertile & Middle tertile & Highest tertile & Lowest tertile & Middle tertile & Highest tertile \\
\hline \multicolumn{7}{|l|}{ Birth weight } \\
\hline \multicolumn{7}{|c|}{ Highest tertile } \\
\hline $\mathrm{n}$ & 34 & 43 & 59 & 40 & 41 & 55 \\
\hline $\mathrm{aOR}$ & 1.35 & 5.15 & 4.66 & 0.47 & 0.98 & 3.56 \\
\hline $95 \% \mathrm{Cl}$ & $0.08-22.85$ & $0.56-46.76$ & $0.52-41.06$ & $0.04-4.80$ & $0.15-6.35$ & $0.88-14.41$ \\
\hline \multicolumn{7}{|c|}{ Middle tertile } \\
\hline $\mathrm{n}$ & 41 & 49 & 48 & 38 & 56 & 44 \\
\hline $\mathrm{aOR}$ & 2.12 & 1.00 & 5.19 & - & 1.00 & 3.11 \\
\hline $95 \% \mathrm{Cl}$ & $0.18-24.72$ & & $0.57-47.32$ & - & & $0.66-14.47$ \\
\hline \multicolumn{7}{|c|}{ Lowest tertile } \\
\hline $\mathrm{n}$ & 61 & 43 & 33 & 59 & 39 & 39 \\
\hline $\mathrm{aOR}$ & 4.40 & 3.76 & 16.35 & 2.01 & 1.16 & 8.11 \\
\hline $95 \% \mathrm{Cl}$ & $0.48-39.98$ & $0.31-44.98$ & $1.66-160.57$ & $0.40-9.95$ & $0.17-7.56$ & $1.68-38.99$ \\
\hline
\end{tabular}

aOR: odds ratio adjusted by sex, gestational age, household income, mother' s employment, prenatal or postnatal environmental tobacco smoke exposure and family history of allergic diseases; BMI: Body Mass Index; Cl: confidence interval.

In logistic regression analysis, children in the lowest birth weight tertile or in the highest BMI tertile at 3 years of age had higher risk of chronic respiratory illness (Table 3). At birth, being in the lowest tertile of birth weight had more than 3 times higher risk of chronic respiratory illness compared to those in the middle tertile $(\mathrm{aOR}=3.97,95 \% \mathrm{CI}=0.94-16.68)$. At 3 years of age, children in the highest BMI tertile were at an increased risk of chronic respiratory illness compared to those in the middle tertile $(\mathrm{aOR}=3.68,95 \% \mathrm{CI}=1.24-10.95)$. Children in the highest BMI tertile also had more than 4 times the risk of asthma compared to those in the middle tertile $(\mathrm{aOR}=4.28,95 \% \mathrm{CI}=1.17-15.57)$.
The risk of chronic respiratory disease was also analyzed by third of birth weight and weight at age 3 (Table 4). It was revealed that those who were in the lowest birth weight tertile but are now in the highest weight tertile had the highest risk of chronic respiratory illness (aOR $=16.35,95 \% \mathrm{CI}=1.66-160.57)$. A similar trend was observed in the analysis of birth weight and BMI. Those who were in the lowest birth weight tertile and now in the highest BMI tertile had more than 8 times the risk of chronic respiratory illness compared to those who had maintained the middle tertile status (aOR $=8.11,95 \% \mathrm{CI}=1.68-38.99)$. Children who were in the lowest birth weight tertile and remained in the lowest 
Table 5. The relationship of birthweight, current weight and body mass index (BMI) at age three to the odds ratio (OR) of chronic respiratory disease

\begin{tabular}{llrll}
\hline Birthweight & Weight & \multicolumn{1}{c}{ OR } & \multicolumn{1}{c}{ BMI } & OR \\
\hline Middle tertile & Middle tertile & 1.00 & Middle tertile & 1.00 \\
Middle tertile & Highest tertile & 5.19 & Highest tertile & 3.11 \\
Lowest tertile & Middle tertile & 3.76 & Middle tertile & 1.16 \\
Lowest tertile & Highest tertile & 16.35 & Highest tertile & 8.11 \\
\hline \multicolumn{4}{c}{ Observed OR: 16.35} & Observed OR: 8.11 \\
& Expected OR: & Expected OR: \\
& Additive Model: & Additive Model: \\
& $5.19+3.76-1.00=7.95$ & $3.11+1.16-1.00=3.27$ \\
& Multiplicative Model: & Multiplicative Model: \\
& $5.19 \times 3.76=19.51$ & & $3.11 \times 1.16=3.61$ \\
\end{tabular}

tertile had higher risk compared to those who had maintained the middle tertile status, however, it was without statistical significance.

Interaction of birthweight and weight at age three can be evaluated by comparing the observed and expected joint effects (Table 5). The observed joint odds ratio of birth weight and weight at age three is larger than the expected odds ratio only on an additive scale. On the other hand, the observed joint odds ratio of birthweight and BMI at age three is larger than the expected odds ratio on both the additive and multiplicative scale.

\section{DISCUSSION}

This study suggested that children with lower birth weight or higher BMI were at an increased risk of chronic respiratory illness. In addition, children who were initially in the lowest birth weight tertile but are now in the highest weight tertile had more than 16 times higher risk of chronic respiratory illness compared to those who remained in the middle tertile. The effect of current weight on chronic respiratory illness in children was modified by birth weight in an additive manner.

The results of this study confirmed the findings of previous studies that higher weight or BMI is associated with an increased risk of chronic respiratory illness. In similar studies, children with higher body weight or BMI were at 1.5-3.0 times higher risk of asthma $[1,25]$ and wheezing [9]. In many cross-sectional studies, this was interpreted as asthma preceding obesity due to lack of exercise among such asthmatic children. However, this explanation was discouraged by numerous longitudinal studies which suggest that the risk of newly onset asthma is significantly higher in overweight and obese children $[3,6,26,27]$. The temporal relationship of obesity preceding asthma was further supported by the speculation that infancy and early childhood are time periods where the effect of sedentary lifestyle on obesity is less prominent [22]. Moreover, weight loss in obesity was shown to improve lung function and decrease symptoms and morbidity of respiratory illness [28,29].

Obesity causes many physiologic changes associated with asthma. Adipose tissue is a source of nearly $25 \%$ of the body's circulating interleukin- 6 as well as other inflammatory cytokines such as leptin, interleukin-18, and tumor necrosis factor- $\alpha$ [11]. Increase in fat mass may contribute to systematic inflammation through elevated cytokine production and such increase in systemic or local inflammation may contribute to airway inflammation, which is an important element in asthma pathophysiology [18]. Obesity is also thought to cause mechanical complications such as a decrease in airway caliber, chest wall compliance, respiratory muscle strength, and lung volume due to accumulation of fat in and around the chest and abdomen [30]. Narrowing of the airways partly contributes to bronchial hyperresponsiveness.

Being born with lower than optimum birth weight is associated with various chronic conditions such as coronary heart disease, stroke, hypertension, and diabetes [31,32], whereas its association with respiratory outcome has been somewhat inconsistent. In this study, children with suboptimal birth weight had the highest risk of chronic respiratory disease. There were no significant association between birth weight and respiratory outcomes in some previous studies $[2,16]$ whereas higher birth weight was associated with asthma in others [4,14]. However, the results of many longitudinal studies suggested that children with suboptimal birth weight have higher risk of respiratory diseases and respiratory symptoms such as wheezing, cough, and respiratory infection [3].

Birth weight is an indicator of prenatal growth, nutritional status in utero, maternal health, and placental function which are all significantly associated with the development of fetal respiratory and immune system $[3,14,19,24]$. Airway branching is completed by midgestation and alveolization starts before birth. Restricted prenatal growth could, therefore, result in an impairment of lung and airway development or diminished lung function [21]. Evidence from animal studies suggested that impaired growth in utero is associated with diminished surfactant activity, lung protein component, lung cellularity, and respiratory drive [33]. It is also suggested that children with lower birth weight are more susceptible to respiratory tract infection and subsequent lung damage, which could partly be attributed to the relatively suboptimal immune development in these 
children [34].

This study showed that children who were in the lowest birth weight tertile but are now in the highest weight tertile had a significantly higher risk of chronic respiratory illness compared to those who had maintained the mid-third status at both birth and age 3 . This result was in line with previous studies which suggest that early life weight gain is associated with numerous chronic conditions of later life such as coronary heart disease [17,31,35], hypertension [36], and diabetes [19,37]. Many epidemiological studies confirmed that children who have high weight gain in early infancy have higher BMI and central fat distribution typical of childhood obesity $[12,21,34,38$, 39]. This is explained as children with lower birth weight trying to compensate with rapid weight gain in infancy and thus leading into childhood obesity [34]. Children with such weight gain pattern were suggested to have an increased risk of asthma exacerbations and impaired lung function $[20,21]$.

A limitation of this study was that there is potential misclassification bias because the presence of respiratory illness and symptoms were reported by the parents to whom the questionnaire was administered. Misclassification may also have been caused by the difficulty of diagnosing asthma in young children. Young children submit with various wheezing phenotypes and the mechanism underlying these different phenotypes differ. As early onset transient wheezing is common among young children under 3 years of age, there is a possibility that transient wheezing, rather than persistent wheeze or true asthma, may have been diagnosed as asthma in children. Early transient wheezing is thought to be a temporary condition of infancy not necessarily associated with increased risk of asthma in later life [40]. Therefore in this study, asthma was defined as only those who had been diagnosed of asthma from a doctor or those who had taken anti-asthmatic medication.

There was also a possibility that tertile cut-off points used in this study may not necessarily correspond to those of a more representative sample. We had carried out an additional analysis with clinically relevant cut-off values ( $\leq 2500 \mathrm{~g}, 2500-4000 \mathrm{~g}, \geq 4000 \mathrm{~g}$ ). The lowest group whose birth weight was lower than $2500 \mathrm{~g}$ contained $71 \%$ of the participants of the original lowest tertile group and the results were similar in terms of effect size and significance. There were 7 participants whose birth weight was higher than $4000 \mathrm{~g}$, however, their risk of chronic respiratory illness was higher (aOR $=4.29,95 \% \mathrm{CI}=0.34-53.79$ ). Those who were initially born with less than $2500 \mathrm{~g}$ but are now in the highest tertile of weight or BMI had highest risk of chronic respiratory illness with effect size and significance similar to the original analysis.

Due to the fact that 422 (29\%) children were included in the final analysis among the initial enrollment of 1436 children, there is a possibility of a selection bias arising from the difference between children who were included and those who were not. However, we carried out an additional analysis to find out that perinatal factors such as gestational age, birth weight, and birth length did not differ significantly between the two groups and assumed that such selection bias would most likely be minimal.

Lastly, a wide confidence interval may suggest relatively low precision which warrants further study.

A major strength of this study was that, to our knowledge, this was the first study that had evaluated the effect of current weight, birth weight, and their interaction on chronic respiratory illness in Korean children. In addition, the follow up of the weight change from birth to three years of age and analyzing it in association with current respiratory illness allows better establishment of the temporal relationship. Sex, gestational age, family history of allergic diseases, ETS exposure, and socioeconomic factors such as household income and mother's employment status were identified as potential confounding factors from other previous studies $[1-4,9,11-13]$ and were effectively controlled for in the analysis.

This study suggests that children with lower birth weight or higher BMI were at an increased risk of chronic respiratory illness. In addition, children who were initially in the lowest birth weight tertile but are now in the highest weight tertile had higher risk of chronic respiratory illness compared to those who remained in the middle tertile.

\section{CONFLICT OF INTEREST}

The authors have no conflict of interest to declare on this study.

\section{REFERENCES}

1. Flaherman V, Rutherford GW. A meta-analysis of the effect of high weight on asthma. Arch Dis Child 2006; 91(4): 334339.

2. Taveras EM, Camargo CA Jr, Rifas-Shiman SL, Oken E, Gold DR, Weiss ST, et al. Association of birth weight with asthma-related outcomes at age 2 years. Pediatr Pulmonol 
2006; 41(7): 643-648

3. Caudri D, Wijga A, Gehring U, Smit HA, Brunekreef B, Kerkhof M, et al. Respiratory symptoms in the first 7 years of life and birth weight at term: the PIAMA Birth Cohort. Am J Respir Crit Care Med 2007; 175(10): 1078-1085.

4. Sin DD, Spier S, Svenson LW, Schopflocher DP, Senthilselvan A, Cowie RL, et al. The relationship between birth weight and childhood asthma. Arch Pediatr Adolesc Med 2004; 158(1): 60-64.

5. Hong SJ, Ahn KM, Lee SY, Kim KE. The prevalences of asthma and allergic diseases in Korean children. Korean $J$ Pediatr 2008; 51(4): 343-350. (Korean)

6. Camargo CA Jr, Weiss ST, Zhang S, Willett WC, Speizer FE. Prospective study of body mass index, weight change, and risk of adult-onset asthma in women. Arch Intern Med 1999; 159(21): 2582-2588.

7. Chen Y, Dales R, Krewski D, Breithaupt K. Increased effects of smoking and obesity on asthma among female Canadians: the National Population Health Survey, 19941995. Am J Epidemiol 1999; 150(3): 255-262.

8. Beckett WS, Jacobs DR Jr, Yu X, Iribarren C, Williams OD. Asthma is associated with weight gain in females but not males, independent of physical activity. Am J Respir Crit Care Med 2001; 164(11): 2045-2050.

9. Schachter LM, Peat JK, Salome CM. Asthma and atopy in overweight children. Thorax 2003; 58(12): 1031-1035.

10. Musaad SMA, Patterson T, Ericksen M, Lindsey M, Dietrich K, Succop P, et al. Comparison of anthropometric measures of obesity in childhood allergic asthma: central obesity is most relevant. J Allergy Clin Immunol 2009; 123(6): 1321-1327.

11. Gilliland FD, Berhane K, Islam T, McConeell R, Gauderman WJ, Gilliland SS, et al. Obesity and the risk of newly diagnosed asthma in school-age children. Am J Epidemiol 2003; 158(5): 406-415.

12. Ong KK, Dunger DB. Birth weight, infant growth and insulin resistance. Eur J Endocrinol 2004; 151(Suppl 3): U131-U139.

13. Lee H, Yoon SJ, Ahn H, Ha M, Koh KS, June KJ. A Survey on prenatal environmental risk factors for mothers of low birth weight infants in Asan-city. Korean J Prev Med 2004; 37(1): 11-16.

14. Leadbitter P, Pearce N, Cheng S, Sears MR, Holdaway MD, Flannery EM, et al. Relationship between fetal growth and the development of asthma and atopy in childhood. Thorax 1999; 54(10): 905-910.

15. Dik N, Tate RB, Manfreda J, Anthonisen NR. Risk of physician-diagnosed asthma in the first 6 years of life. Chest 2004; 126(4): 1147-1153.

16. Yuan W, Basso O, Sorensen HT, Olsen J. Fetal growth and hospitalization with asthma during early childhood: a follow-up study in Denmark. Int J Epidemiol 2002; 31(6): 1240-1245.

17. Eriksson JG, Forsén T, Tuomilehto J, Winter PD, Osmond C, Barker DJ. Catch-up growth in childhood and death from coronary heart disease: longitudinal study. $B M J$ 1999; 318(7181): 427-431.

18. Tzoulaki I, Jarvelin MR, Hartikainen AL, Leinonen M, Pouta A, Paldanius M, et al. Size at birth, weight gain over the life course, and low-grade inflammation in young adulthood: northern Finland 1966 Birth Cohort Study. Eur Heart J 2008; 29(8): 1049-1056.

19. Forsén T, Eriksson J, Tuomilehto J, Reunanen A, Osmond C, Barker D. The fetal and childhood growth of persons who develop type 2 diabetes. Ann Intern Med 2000; 133(3): 176-182.

20. Turner S, Zhang G, Young S, Cox M, Goldblatt J, Landau $\mathrm{L}$, et al. Associations between postnatal weight gain, change in postnatal pulmonary function, formula feeding and early asthma. Thorax 2008; 63(3): 234-239.

21. Lucas JS, Inskip HM, Godfrey KM, Foreman CT, Warner JO, Gregson RK, et al. Small size at birth and greater postnatal weight gain: relationships to diminished infant lung function. Am J Respir Crit Care Med 2004; 170(5): 534-540.

22. Mai XM, Gaddlin PO, Nilsson L, Leijon I. Early rapid weight gain and current overweight in relation to asthma in adolescents born with very low birth weight. Pediatr Allergy Immunol 2005; 16(5): 380-385.

23. Hancox RJ, Poulton R, Greene JM, McLachlan CR, Pearce MS, Sears MR. Associations between birth weight, early childhood weight gain and adult lung function. Thorax 2009; 64(3): 228-232.

24. Hong SJ, Kim SW, Oh JW, Rah YH, Ahn YM, Kim KE, et al.The validity of the ISAAC written questionnaire and the ISAAC video questionnaire for predicting asthma associated with bronchial hyperreactivity in a group of 1314 year old Korean schoolchildren. J Korean Med Sci 2003; 18(1): 48-52.

25. von Mutius E, Schwartz J, Neas LM, Dockery D, Weiss ST. Relation of body mass index to asthma and atopy in children: the National Health and Nutrition Examination Study III. Thorax 2001; 56(11): 835-838.

26. Castro-Rodriguez JA, Holberg CJ, Morgan WJ, Wright $\mathrm{AL}$, Martinez FD. Increased incidence of asthmalike symptoms in girls who become overweight or obese during the school years. Am J Respir Crit Care Med 2001; 163(6): 1344-1349.

27. Chinn S. Obesity and asthma: evidence for and against a causal relation. J Asthma 2003; 40(1): 1-16.

28. Stenius-Aarniala B, Poussa T, Kvarnström J, Grönlund EL, Ylikahri M, Mustajoki P. Immediate and long term effects of weight reduction in obese people with asthma: randomised controlled study. BMJ 2000; 320(7238): 827832.

29. Weiner P, Waizman J, Weiner M, Rabner M, Magadle R, Zamir D. Influence of excessive weight loss after gastroplasty for morbid obesity on respiratory muscle performance. Thorax 1998; 53(1): 39-42.

30. Litonjua AA, Sparrow D, Celedon JC, DeMolles D, Weiss 
ST. Association of body mass index with the development of methacholine airway hyperresponsiveness in men: the Normative Aging Study. Thorax 2002; 57(7): 581-585.

31. Barker DJ, Godfrey KM, Fall C, Osmond C, Winter PD, Shaheen SO. Relation of birth weight and childhood respiratory infection to adult lung function and death from chronic obstructive airways disease. BMJ 1991; 303(6804): 671-675.

32. Frankel S, Elwood P, Sweetnam P, Yarnell J, Smith GD. Birthweight, body-mass index in middle age, and incident coronary heart disease. Lancet 1996; 348(9040): 14781480.

33. Lin Y, Lechner AJ. Surfactant content and type II cell development in fetal guinea pig lungs during prenatal starvation. Pediatr Res 1991; 29(3): 288-291.

34. Eriksson M, Tynelius P, Rasmussen F. Associations of birthweight and infant growth with body composition at age 15--the COMPASS study. Paediatr Perinat Epidemiol 2008; 22(4): 379-388.

35. Singhal A, Cole TJ, Fewtrell M, Deanfield J, Lucas A. Is slower early growth beneficial for long-term cardiovascular health? Circulation 2004; 109(9): 1108-1113.
36. Huxley RR, Shiell AW, Law CM. The role of size at birth and postnatal catch-up growth in determining systolic blood pressure: a systematic review of the literature. $J$ Hypertens 2000; 18(7): 815-831.

37. Bhargava SK, Sachdev HS, Fall CH, Osmond C, Lakshmy $\mathrm{R}$, Barker DJ, et al. Relation of serial changes in childhood body-mass index to impaired glucose tolerance in young adulthood. N Engl J Med 2004; 350(9): 865-875.

38. Stettler N, Zemel BS, Kumanyika S, Stallings VA. Infant weight gain and childhood overweight status in a multicenter, cohort study. Pediatrics 2002; 109(2): 194199.

39. Ekelund U, Ong K, Linné Y, Neovius M, Brage S, Dunger $\mathrm{DB}$, et al. Upward weight percentile crossing in infancy and early childhood independently predicts fat mass in young adults: the Stockholm Weight Development Study (SWEDES). Am J Clin Nutr 2006; 83(2): 324-330.

40. Rusconi F, Galassi C, Corbo GM, Forastiere F, Biggeri A, Ciccone $\mathrm{G}$, et al. Risk factors for early, persistent, and lateonset wheezing in young children. SIDRIA Collaborative Group. Am J Respir Crit Care Med 1999; 160(5 Pt 1): 1617-1622. 